\title{
Andersson Type III Lesion Treated by Double Approach
}

\section{Villanueva $C^{*}$}

Clinical Pilar, Spain

\begin{abstract}
Andersson lesion is a destructive vertebral or discovertebral lesion that occurs as a late noninflamatory episode in ankylosing spondylitis. The lesion was first reported by in 1937. Since then many cases have been reported.
\end{abstract}

\section{Introduction}

Incidence of this lesion has been reported about $5 \%[1,2]$ but other series have reported higher incidence (17\%).

Dihlmann W and Delling G [3] and Cawley et al. [4] have attempted a classification into inflammatory and non-inflammatory types. Cawley [4] also describes the topography of lesion according to whether the lesion was localized or extensive. Localized lesions occurred either at the rim of the vertebra or in a small circumscribed area of end plate while extensive lesions involved both areas and spread across the whole disc margin. Lesion in spines with advanced ossification might be prorogued by minor trauma however there are some cases were traumatic antecedent has not be proven

The most evident radiographic feature was the irregular disappearance of the vertebral end plate on both the upper and the lower border of the disc. The border between disc and bone was ragged and hazy instead of smooth and sharp, while reactive sclerosis extended for a varying depth into the vertebral body. The disc space was conspicuously more radiolucent than its neighbors which were usually fused. Neurological complications resulting from discovertebral destruction have rarely been reported despite sometimes extensive radiological changes [5] and the severity of symptoms does not always correlate with the severity of pseudarthroses [6].

\section{Case Report}

This is the case of a 35 years old male that was diagnosed from AS at the age of 23. The patient presented severe back pain after fall at home. The patient was visited by his GP. Initial X-rays (Figure 1) showed evident radiolucency of the L1-L2 disc. The rest of the spine showed advanced ankylosis. The patient was treated by a rheumatologist with NSAID and then referred to a pain clinic without any improvement. Nine months later, Radiological control demonstrated increased destruction around the disc L1-L2 with a significant segmental kyphosis of 25 degrees at that level (Figure 2). Three months later (one year since the initial X-rays) the patient continued clinical deterioration complaining from an incapacitating back pain and subjective sensation of abnormal mobility in the thoracolumbar area. Neurological exploration was strictly normal. Xrays demonstrated increased destruction at the level of the initial lesion but the sagittal deformity was easily reductible (Figure 3). The patient was finally referred to our Unit. No Increased systemic inflammatory responses, including elevation of ESR and CRP, were found in the preoperative tests.

The patient was treated with staged circumferential fusion. For the first step, posterior pedicle instrumentation above and below of the affected segment was applied (T11, T12 and L2, L3). Correction of the angular deformity and the collapse of the disc space, were easily obtained. In a second stage, anterior interbody fusion was performed with a strut allograft of tibia diaphysis. All fibrous tissue and necrotic bone were excised and were sent for histopathologic and microbiologic study. Vertebral bodies showed irregular destruction of endplates with sclerotic bony spicules.

After surgery, patient rest in bed for three days and ambulated in a plastic TLSO brace which was worn for 12 weeks. The patient had immediate pain relief. Postoperative course was uneventful. Radiographic control showed complete correction of the sagittal deformity. Patient's bacteriologic testing showed no evidence of infection. Microscopic findings showed hypovascular fibrous tissue with fibrinoid necrosis and chondrodysplasia. One year after surgery the patient continues free of pain, very satisfied with the result and the last control shows a minor collapse of the anterior column with an acceptable segmental kyphosis of 5 degrees (Figures 4 and 5).

\section{Discussion}

Pathogenesis of the destructive lesions is disputable: Pathologic

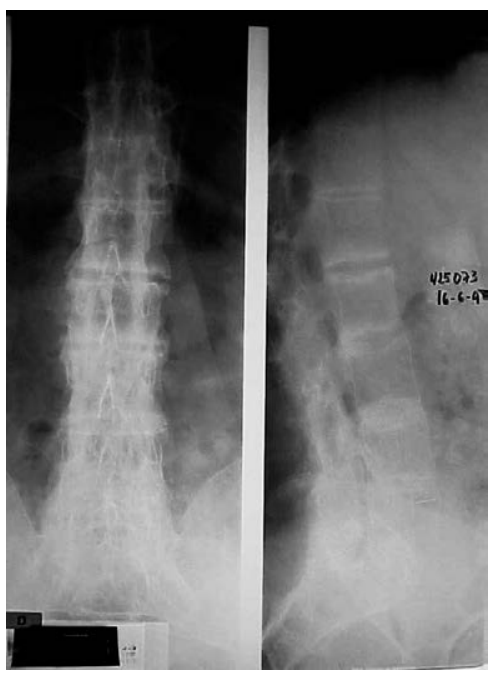

Figure 1: Initial x-rays, increased disc space/radiolucency.

*Corresponding author: Villanueva C, Clinical Pilar, Spain, Tel: 93-236-05-00; E-mail: drc.villanueval@gmail.com

Received July 22, 2014; Accepted September 24, 2014; Published September 29, 2014

Citation: Villanueva C (2014) Andersson Type III Lesion Treated by Double Approach. J Trauma Treat 3: 212. doi:10.4172/2167-1222.1000212

Copyright: (c) 2014 Villanueva C. This is an open-access article distributed under the terms of the Creative Commons Attribution License, which permits unrestricted use, distribution, and reproduction in any medium, provided the original author and source are credited. 


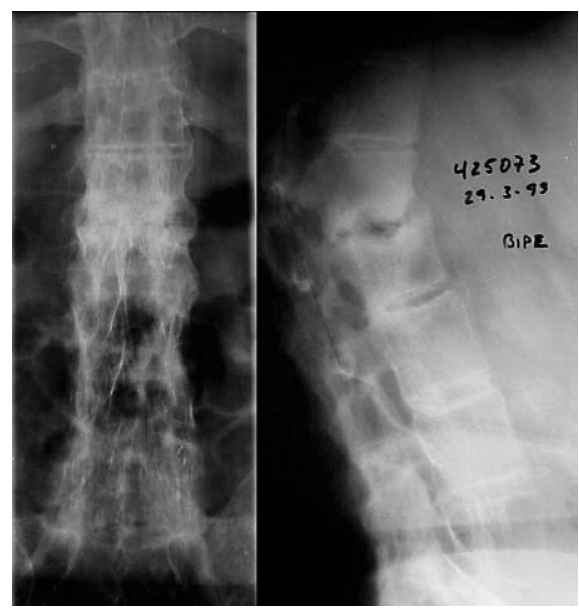

Figure 2: Increased destruction, Kyphosis 20 degrees.

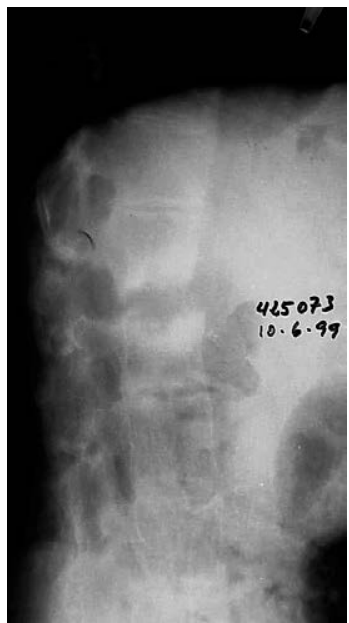

Figure 3: Flexible deformity. Wide destruction.

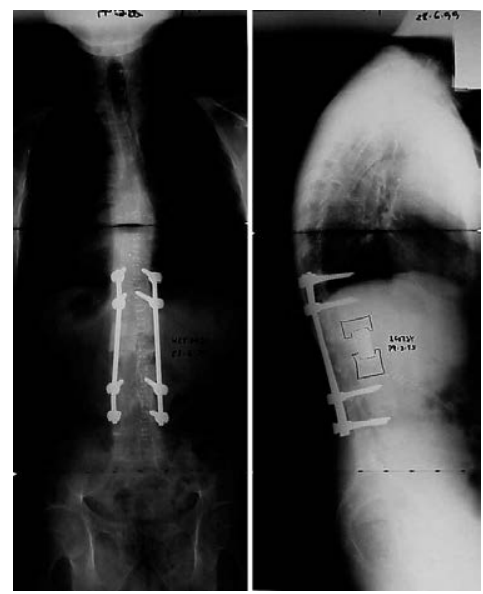

Figure 4: Postoperative X.rays

observations strongly implicate mechanical trauma and pseudarthrosis as initiating and perpetuating causes for extensive discovertebral destruction in ankylosing spondylitis. WU et al. [7] reported their histopathological findings in eight specimens showing extensive discovertebral destructive lesions collected from 35 patients with ankylosing spondylitis. A detailed pathologic study revealed a consistent picture of complete or near-complete destruction of the disc-bone border and the intervertebral disc. The disc was replaced by fibrous tissue and/or fibrocartilage showing moderate to severe fibrinoid necrosis and cystic degeneration. Such changes are characteristic of pseudarthrosis, which may follow either fracture or degeneration of the disc perpetuated by abnormal stress and motion. The reparative process included fibrovascular tissue proliferation from the vertebral bone marrow. Fibrovascular tissue also perforated the vertebral endplate and intervertebral spaces resulting in massive discovertebral destruction. It is difficult to elucidate if uncontrolled disease activity may have an important additional role like some authors proposed. However history of trauma or an inflammatory reaction was not present in all of reported AS patients with pseudarthrosis, although they might be found occasionally.

Other possible mechanisms for the formation of pseudarthrosis have been suggested. Some authors [6-8] hypothesized that since spinal ossification in AS may not be contiguous, the skipped segments that have not become completely ossified are exposed to increased stress due to the long ankylosed segments. The mechanical stresses may cause increased wear at the disco-vertebral junction, followed by fibrous repair.

Regarding pathogenesis of the pain, our case with immediate pain relief after the first surgery of posterior stabilization seems to support that the pain was related to the hypermobility of the lesion rather than to the pseudartrosis/inflammatory process.

Destructive lesions in AS were also classified by Cawley (4) into three types:

Type 1 lesions are localized at the central subchondral portions of the discovertebral junction with migration of the discal content into the vertebral body and this can occur in both ankylosed and nonankylosed spines.

Type 2 are peripheral localized lesions occurring in the anterior or posterior part of discovertebral junction. The anterior lesion is attributed to collapse of osteoporotic anterior vertebral margin as occurs in osteoporotic kyphosis and also alternatively to injury to the

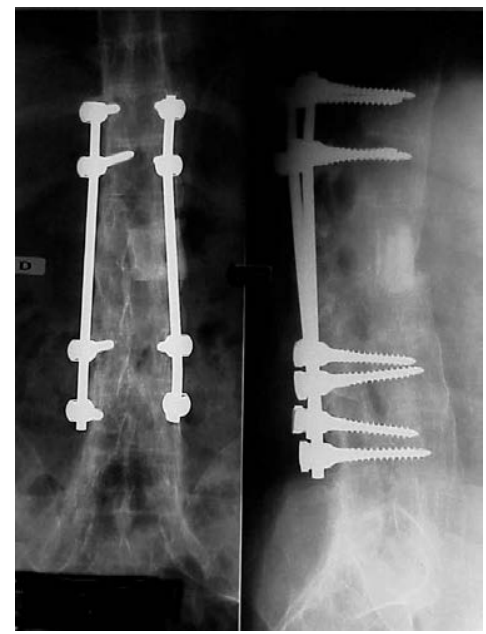

Figure 5: One year post-operative. 
anterior fibers of annulus fibrosus leading to invasion and replacement of discal material by vascular fibrous tissue as in senile kyphosis.

Type 3 Destruction of the whole discovertebral junction of two adjacent vertebral bodies occurs in patients with advanced ankylosis. There may be a history of trauma and associated fracture through the ankylosed portion. Looking at the present case it seems that type three would be the final evolution of the initial lesion, central (type 1) or peripheral (type 2), rather than a different type of lesion.

These lesions have been observed in the early and late phases of the disease and occur in traumatic and non-traumatic situations [9]. But Park YS et al. [2] pointed out the importance of the etiology on the prognostic of the lesion. They retrospectively reviewed 622 patients with ankylosing spondylitis. In all, 33 patients $(5.3 \%)$ had these lesions, affecting 100 spinal segments. Inflammatory lesions were found in 91 segments of 24 patients (3.9\%) and traumatic lesions in nine segments of nine patients $(1.4 \%)$ he inflammatory lesions were associated with: recent-onset disease; a low modified Stoke ankylosing spondylitis spine score (mSASSS) due to incomplete bony ankylosis between vertebral bodies; multiple lesions; inflammatory changes on MRI; reversal of the inflammatory changes and central bony ankylosis at follow-up; a good response to anti-inflammatory drugs.

Traumatic lesions were associated with: prolonged disease duration; a high mSASSS due to complete bony ankylosis between vertebral bodies; a previous history of trauma; single lesions; acute kyphoscoliotic deformity with the lesion at the apex; instability, and the need for operative treatment due to that instability Park YS et al. concluded that it is essential to distinguish between inflammatory and traumatic Andersson lesions, as the former respond to medical treatment whereas the latter require surgery.

Treatment for cases with small destruction can be managed with internal [10] or external immobilization with cast [11] but cases with severe destruction would need a complete biomechanical reconstruction with anterior support [12]. Due to the usual osteoporosis of the AS, posterior instrumentation with multiple anchors would be preferable. Fixed sagittal deformities would need a more aggressive treatment with posterior osteotomies or with combined approaches [13].

\section{Conclusion}

Andersson lesion should be suspected in Ankylosing Spondylitis patients, complaining from persistent back pain, especially after minor trauma. Diagnosis is very evident with conventional image exploration (radiography, MRI). Appropriate initial treatment, immobilization with cast or percutaneous stabilization can solve the problem. In cases with massive anterior destruction, surgical reconstruction of the anterior and middle columns seems to be mandatory.

\section{References}

1. Andersson O (1937) Rontgenbilden vid spondyloarthritis ankylopoetica. Nord Med14: 2000-2002

2. Park YS, Kim JH, Ryu JA, Kim TH (2011) The Andersson lesion in ankylosing spondylitis: distinguishing between the inflammatory and traumatic subtypes. $J$ Bone Joint Surg Br 93: 961-966.

3. Dihlmann W, Delling G (1978) Disco-vertebral destructive lesions (socalled Andersson lesions) associated with ankylosing spondylitis. Skeletal Radiol. 3:10-16.

4. Cawley MI, Chalmers TM, Kellgren JH, Ball J (1972) Destructive lesions of vertebral bodies in ankylosing spondylitis. Ann Rheum Dis 31: 345-358.

5. Jobanputra P, Kirkham B, Duke O, Crockard A, Panayi GS (1988) Discovertebra destruction in ankylosing spondylitis complicated by spinal cord compression. Ann Rheum Dis 47: 344-347.

6. Kim KT, Lee SH, Suk KS, Lee JH, Im YJ (2007) Spinal pseudarthrosis in advanced ankylosing spondylitis with sagittal plane deformity: clinical characteristics and outcome analysis. Spine (Phila Pa 1976) 32: 1641-1647.

7. Wu PC, Fang D, Ho EK, Leong JC (1988) The pathogenesis of extensive discovertebral destruction in ankylosing spondylitis. Clin Orthop Relat Res : 154-161.

8. Fang D, Leong JC, Ho EK, Chan FL, Chow SP (1988) Spinal pseudarthrosis in ankylosing spondylitis. Clinicopathological correlation and the results of anterior spinal fusion. J Bone Joint Surg Br. 3: 443-447

9. Dunn N, Preston B, Lloyd JK (1985) Unexplained acute backache in long standing ankylosing spondylitis. Br Med J 291:1632-1634.

10. Wang G, Sun J, Jiang Z, Cui X (2011) The surgical treatment of Andersson lesions associated with ankylosing spondylitis. Orthopedics 34: e302-306.

11. Rasker JJ, Prevo RL, Lanting PJ (1996) Spondylodiscitis in ankylosing spondylitis, inflammation or trauma? A description of six cases. Scand J Rheumatol 25: 52-57.

12. Kuo SC, Kao HC, Liu CL, Yu WK, Lo WH (1995) Surgical treatment of extensive discovertebral destruction in ankylosing spondylitis: a report of two cases. Zhonghua Yi Xue Za Zhi (Taipei) 55: 189-194.

13. Kim KT, Lee SH, Suk KS, Lee JH, Im YJ (2007) Spinal pseudarthrosis in advanced ankylosing spondylitis with sagittal plane deformity: clinical characteristics and outcome analysis. Spine (Phila Pa 1976) 32: 1641-1647. 